\title{
Dialogue about health behaviour change in people with mental illness and diabetes: Is a collaborative approach feasible?
}

Nana F. Hempler and Regitze A. S. Pals, Steno Diabetes Center Copenhagen, Diabetes Management Research, Denmark Lone Oest, Vinie D. H. Levisen, University College South Denmark Naja R. Krogh, Region of Southern Denmark

\section{PROBLEM STATEMENT}

Compared to the general population, people with mental illness are at higher risk of developing overweight and type 2 diabetes, due to medication, sedentary lifestyle etc.

\section{SUPPORT FROM EDUCATORS}

In people with mental illness, support from educators is crucial to engage in sustainable health behaviour change. However, educators are often socialised into a biomedical approach and trained to be experts, which has been shown to have limited effects on behaviour change in their target groups.

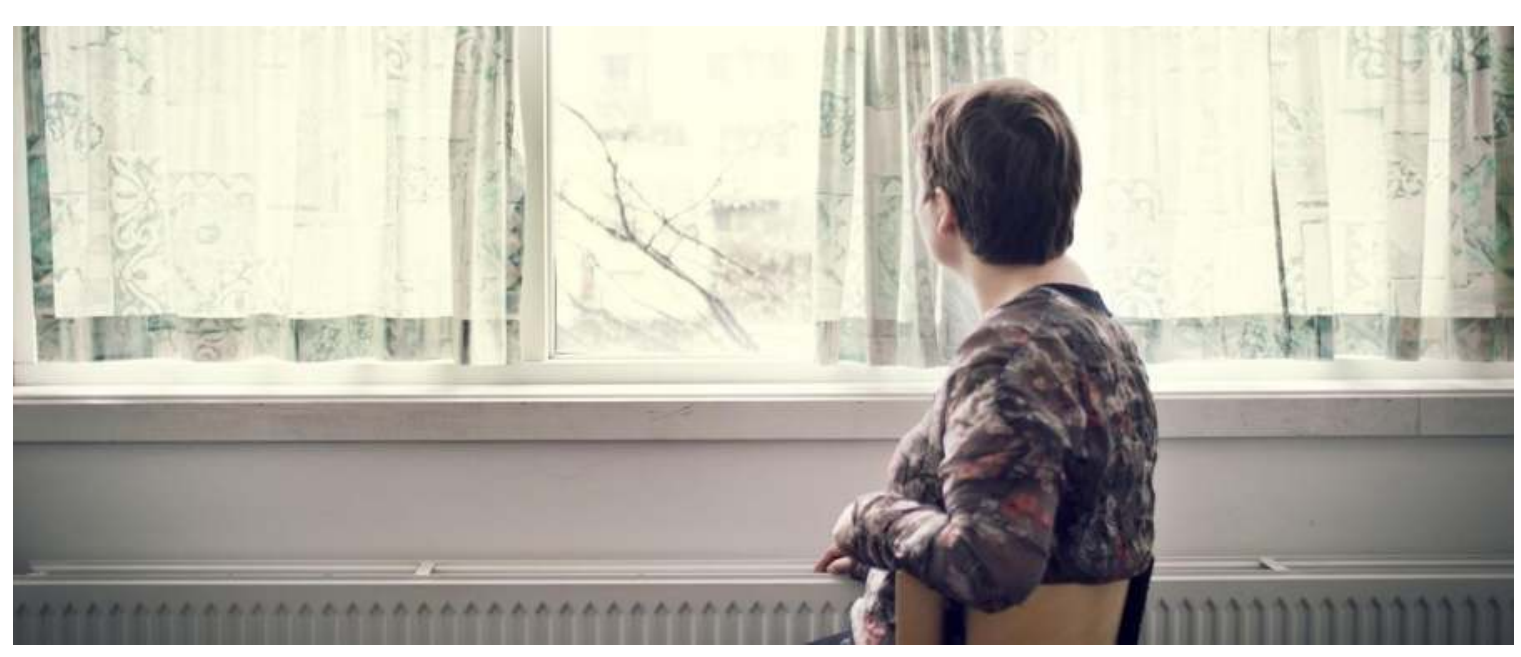

\section{RESEARCH-BASED APPROACH}

The collaborative approach is based on two empirically grounded health education models, a guide and seven dialogue tools was developed in co-creation with people with mental illness and (risk of) type 2 diabetes.

\section{DIALOGUE TOOLS}

The dialogue tools addressed:

- Psychosocial and physical health

- Social relations

- Perspectives and thoughts about healthy life

- Balancing expectations about the content and setting of the health promotion activity

- Strategies to explore motivation for behaviour change

\section{PROFESSIONAL DEVELOPMENT}

A three-day course in the new, collaborative approach was held. Participants included:

- 54 educators. Mainly nurses, physiotherapists and social workers

- People with mental illness who participated in the course as discussion partners

The course consisted of:

- Theoretical introduction

- Practical training with the tools

- Communication training through role plays

- Experience sharing with other educators and people with mental illness

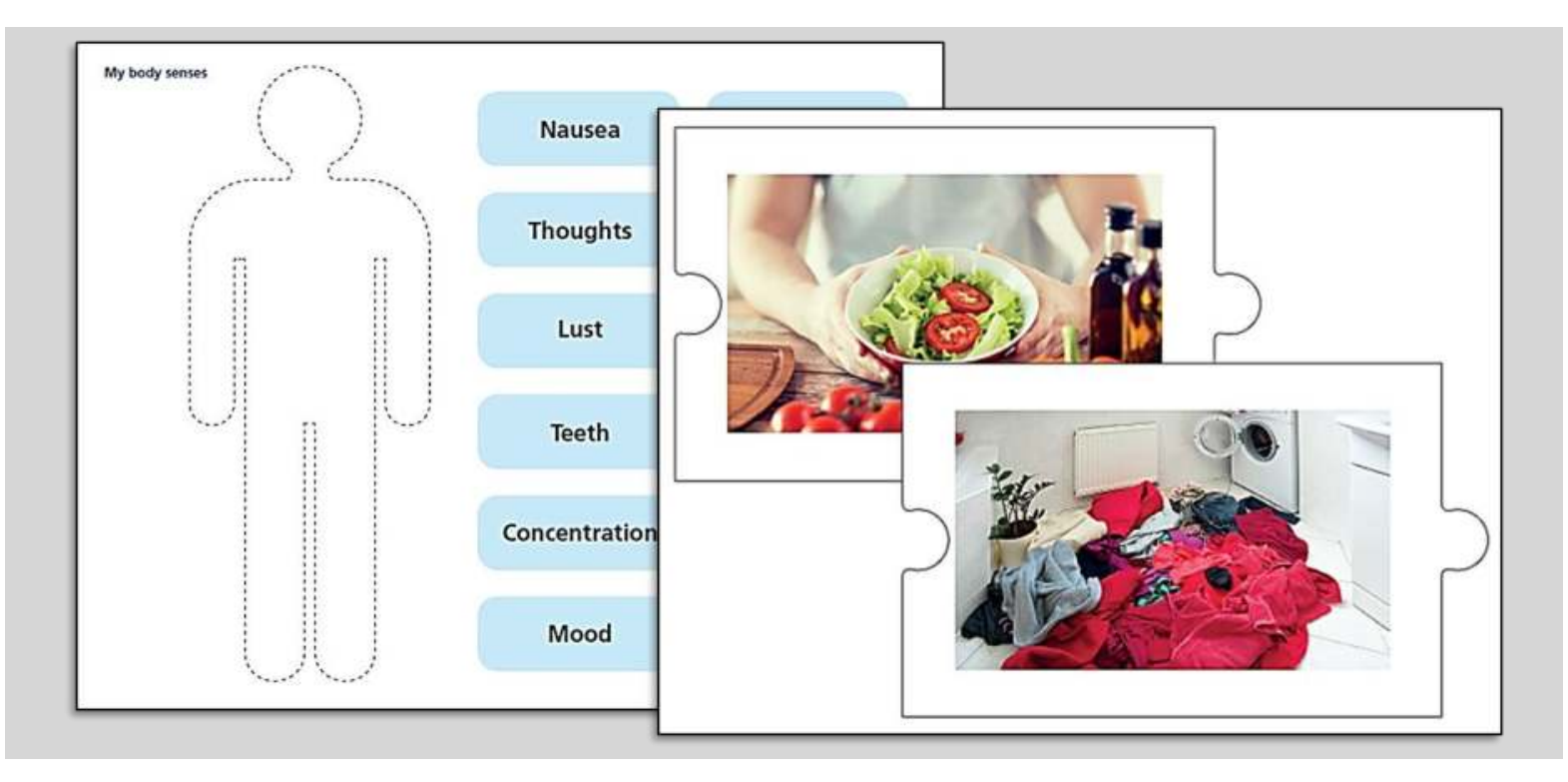

Examples of dialogue tools

"My body senses" and "The good life"

\section{FEASIBILITY RESULTS}

INTEGRATNG THE NEW APPROACH

Educators integrated tools in their practice in:

- Group-based and individual activities

- Communication was based on a particular topic such as exercise and health promotion in general

The collaborative approach facilitated:

- A high level of dialogue

- Active involvement of the target group

RELEVANCE OF THE TOOLS FOR TARGET GROUP

The target group reported that the tools:

- Articulated their resources

- Facilitated dialogue about concrete options related to health behaviour change

- Stimulated their ability to concentrate and stay focused throughout the activity

\section{APPLICABILITY OF NEW APPROACH}

The professionals, who participated in the course were pleased with the new approach, and found it relevant in their daily practice:

- $89.3 \%$ reported that the approach to a moderate/high degree had improved their collaborative skills

- $93.5 \%$ reported that the new approach was wellsuited for their practice

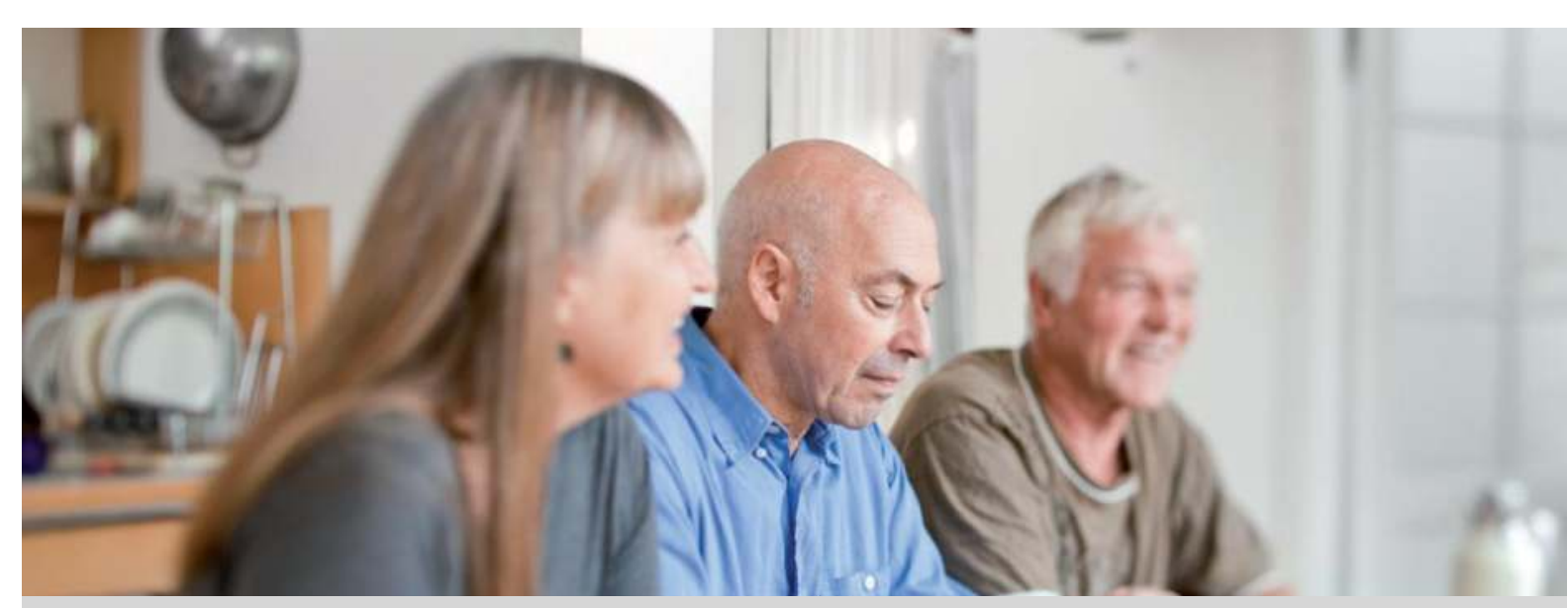

A collaborative approach based on dialogue tools and new communication techniques fostered collaboration between educators and people with mental illness and (risk of) type 2 diabetes. Implementation of the approach requires a substantial focus on training of educators in communication techniques and more dialogue with the managers of the educators. 